\title{
Pulmonary functions of commercial tricyclists (Keke Napep riders) in Enugu State, Nigeria
}

\author{
Chidiebele P Ojukwu' ${ }^{1}$, Adaora J Okemuo ${ }^{1}$, Chinwe V Madu ${ }^{1}$, Rita N Ativie ${ }^{1}$, \\ Chukwu Sylvester Caesar', Anekwu Emelie Moris ${ }^{2}$
}

1. Department of Medical Rehabilitation, College of Medicine, University of Nigeria Enugu, Nigeria.

2. Department of Physiotherapy, Federal Teaching Hospital Abakaliki, Ebonyi State, Nigeria.

\section{Emails:}

Adaora J Okemuo: adaora.okemuo@unn.edu.ng; Chinwe V Madu: vivmadu93@gmail.com; Rita N Ativie: rita.ativie@unn.edu.ng; Chukwu Sylvester Caesar: sylvermine@gmail.com; Anekwu Emelie Moris: emelieanekwu@gmail.com

\begin{abstract}
Background: Tricyclists are continuously exposed to vehicle emissions and other environmental pollutants, due to the nature of their job and vehicle design, which may be hazardous to health. However, there is paucity of data on the pulmonary functions of commercial tricyclists in Nigeria, which should have provided insight into any relevant health concerns in this population, hence this study.

Objectives: This study evaluated the pulmonary functions of tricyclists, in comparison with those of age-matched non-tricyclists.

Methods: Two hundred and ten (210) [150 commercial tricyclists; 60 non-tricyclists] males (aged 20-65years) participated in this unmatched case-control study in Enugu, Enugu state, Nigeria. Their pulmonary functions [Forced Vital Capacity (FVC), Forced Expiratory Volume in one second (FEV1), Peak Expiratory Flow Rate (PEFR)] were assessed using a computerized spirometer. Independent T-test and Pearson Chi-square were used to analyze data at a significant level of $\mathrm{P}<0.05$.

Results: Cough $(46.0 \%)$ and dust allergies $(40.7 \%)$ were the commonest reported respiratory symptoms among tricyclists. There were significant differences in the FVC $(\mathrm{P}<0.001)$, FEV1 $(\mathrm{P}<0.001)$ and PEFR $(\mathrm{P}<0.001)$ between the two groups, with tricyclists showing lower pulmonary function values. FEV1/FVC was $<70 \%$ with increased FVC in $83.3 \%$ of the tricyclists, suggesting restrictive pulmonary abnormalities.

Conclusion: Decreased pulmonary function values of commercial tricyclists in this study is suggestive of their predisposition to occupation-related pulmonary disorders, particularly the restrictive patterns.

Keywords: Tricyclists; Keke Napep riders; Pulmonary functionss; Nigeria.

DOI: https://doi.org/10.4314/ahs.v20i2.33

Cite as: Ojukwn CP, Okemuo AJ, Madu CV, Ativie RN, Caesar CS, Moris AE. Pulmonary functions of commercial tricyclists (Keke Napep riders) in Enugu State, Nigeria. Afri Health Sci. 2020; 20(2): 798-805. https:/ / doi.org/ 10.4314/ abs.v20i2.33
\end{abstract}

\section{Introduction}

Transportation of persons, goods and services are inevitable necessities in every society. In developing countries like Nigeria, commercial transportation is a key element of economic growth ${ }^{1}$. For commercial purposes,

\section{Corresponding author: \\ Chidiebele P Ojukwu, Department of Medical Rehabilitation, College of Medicine, University of Nigeria Enugu, Nigeria. \\ Tel: +2348039470324 , Email: chidiebele.ojukwu@unn.edu.ng}

the commonest means of transportation in developing countries like Nigeria are buses, taxi cabs, motorcycles and tricycles. The task of tricycling involves riding a three-wheeled vehicle (tricycle) which is also referred to as a keke napep (Nigeria), three-wheeler, tuk-tuk, trishaw, autorick or bajaj (in Indonesia) and auto rickshaw (in India). Recently, tricycling is rapidly becoming more popular as a means of commercial transport in several developing countries, particularly in Asian and African countries $^{2}$. Tricycles exist in several types and designs. The commonest type is characterized by a sheet-metal body or open frame resting on three wheels, canvas roof with drop-down side curtains, small cabin at the front for the driver with handlebar controls, and a car- 
go, passenger, or dual purpose space at the bar ${ }^{3}$. Owing to the heavily congested nature of Nigerian roads, the small size and narrow configuration of tricycles are perfectly suited to navigate the roads. However, there are some possible health risks associated with commercial tricycling, relative to the configuration of tricycles and the environmental exposure of tricyclists to airborne pollutants. One important feature of tricycles is the absence of doors and windows which expose the occupants to uncontrolled environmental pollution during transportation ${ }^{3}$. Secondly, tricycles are commonly powered by gasoline engine or diesel and as a result, are highly polluting. Complete combustion of diesel leads to production of carbondioxide and water ${ }^{4}$. However, in most vehicles and tricycles, combustion is incomplete leading to the formation of various gaseous, liquid and solid compounds including Nitrogen Oxide (NO2), Carbon Mono Oxide (CO), Ozone and Sulphur Dioxide $\left(\mathrm{SO}^{2}\right)^{5}$. These solid particles, referred to as diesel exhaust particulate [DEP] constitute a large proportion of particulate matter (PM) present in the air ${ }^{6}$. In addition, a great number of vehicles on the road are old and poorly maintained ${ }^{7}$, coupled with the fact that there are no or ineffective transport regulating laws in developing countries like Nigeria ${ }^{8}$. Several studies ${ }^{9,10}$ had reported that in other developing countries of sub-Saharan Africa and other parts of the world, such scenario resulted in high levels of traffic-related ambient air pollutants, which have been shown to constitute up to $90-95 \%$ of ambient CO level, $80-90 \%$ of $\mathrm{NO}_{2}, \mathrm{SO}_{2}$, hydrocarbon and PM. In several Nigerian cities, ambient air quality has also been reportedly diminished as a result of exposure to such environmental pollutants ${ }^{11-14}$. Alexander et al. ${ }^{15}$ reported increased concentrations of Lead and some biomarkers of oxidative stress (plasma Malondialdehyde level, catalase activity, vitamins $\mathrm{C}$ and $\mathrm{E}$ levels) among different ages of commercial tricyclists, as compared to non-commercial drivers.

Commercial vehicle drivers, including tricyclists are at increased risk of exposure to diesel exhaust particulates and other particulate matters in the air, resulting from the fact that they spend prolonged periods on the roads ${ }^{16}$. Prolonged exposure to diesel exhausts has been associated with impairment of respiratory and cardiovascular systems ${ }^{17}$. Such respiratory impairments may alter pulmonary functions of affected individuals.

Considering the aforementioned, tricyclists whose occupation involve spending majority of their daily work hours on the road, may be at increased risk of occupational-related respiratory impairments.Some studies ${ }^{18,19}$ had reported pulmonary abnormalities in tricyclists in India. However, health effects of occupational exposure to petroleum vapours and air pollution from vehicular sources have relatively been unexplored among tricyclists in Nigeria despite their high rate of exposure. Considering the preponderance of tricycles in the road transport industry as well as the congestive nature of most Nigerian cities, there is need to evaluate the pulmonary functions of commercial tricyclists in Nigeria. This will provide evidences necessary for the enforcement of policies towards prevention and redution of exposures to occupational hazards which leads to cardiopulmonary diseases. Therefore this study was designed to assess the pulmonary functions of tricyclists, as well as comparing them to their age-matched counterparts.

\section{Method}

A preliminary power analysis showed that a sample size of 50 participants will be needed for the independent $\mathrm{t}$-test at degree of freedom ( $\mathrm{dfb})=1$, to achieve 91\% (0.91) power with a moderate to large effect size of 0.60 at an alha level of 0.0520 . However, a total of two hundred and ten (210) males (150 commercial tricyclists and 60 age-matched non-tricyclists) participated in this unmatched case-control study. Tricyclists were conveniently selected from six tricycle parks (Ogbete market, Mayor market, New market, Gariki, Polo park and Old park) in Enugu, Nigeria. The criteria for including tricyclists in this study included males within the age range of 20-65 years, non-tobacco/cigarette smokers, no history of usage of protective anti-pollution face mask and a minimum of one year working experience with not less than six (6) work hours per day. Participants with history of thoracic surgery, current respiratory and cardiovascular conditions as well as structural abnormalities of the thorax and vertebral column were excluded from this study. Individuals beyond 65 years were excluded from this study in order to eliminate the influence of age on the lung functions ${ }^{21,22}$. The non-tricyclists (control group) were conveniently recruited from male postgraduate hostels of the University of Nigeria, Enugu.

Ethical approval was obtained from the University of Nigeria Health Research and Ethics Committee. The managements of the selected tricycle parks as well as the University of Nigeria postgraduate hostel management gave their permission before the commencement of the study. Each participant was consecutively enrolled to the study respectively, on which basis the written informed consent of the eligible volunteers 
were obtained. Participants' weight (kg) and height (m) were measured with a digital weighing scale (Omron HN 286) and locally constructed stadiometer, respectively. Subsequently, their body mass index $\left(\mathrm{kg} / \mathrm{m}^{2}\right)$ was calculated. Subsequently, a spirometer (CardioGIMA $12 \mathrm{M}$ ) was used to assess the pulmonary functions of the participants. Subjects were familiarized with the test procedures. The mouthpiece of the spirometer was regularly sterilized before each use. The spirometry tests were carried out with the participants in an upright comfortable sitting position, while wearing nose clips $^{23}$. With the mouthpiece of the spirometer firmly attached to the participants' mouths, they were asked to inhale maximally and then exhale maximally into the mouthpiece. Measurements of Forced Vital Capacity (FVC) in Liters (L), Forced Expiratory Volume in the first second (FEV1) in Liters (L), Peak Expiratory Flow Rate (PEFR) in Liters/second (L/second), were directly measured from the spirometer. For each pulmonary function, three consecutive readings were recorded and the best reading was selected and recorded. The classifications of the pulmonary abnormalities were also read off from the spirometer.
Subsequently, the tricyclists' respiratory symptoms over the past six months were investigated, using an adapted questionnaire $^{24}$, comprising a pool of respiratory symptoms.

\section{Data analysis}

Data were summarized using descriptive statistics of mean, standard deviation, percentageand frequency. Inferential statistics applied in the data analysis include independent T-test which was used to make comparisons between the two groups while Pearson Chi-square was used to determine correlation between the duration of exposure (years in tricycling occupation) and pulmonary functions of the tricyclists. Alpha level was set at 0.05 and data were analyzed using Statistical Package for Social Sciences (SPSS).

\section{Result}

A total of 210 males (150 in the study group and 60 in the control group) participated in this study.

The study results showed no significant differences $(\mathrm{p}$ $>0.05)$ in the age, height and weight of participants in the two groups (table 1).

Table 1: Descriptive statistics of the participants.

\begin{tabular}{lcccc}
\hline Variable & Tricyclists & Non-tricyclists & t-value & p-value \\
\hline Age (years) & $33.91 \pm 8.13$ & $31.42 \pm 4.80$ & 1.921 & 0.065 \\
Height (m) & $1.69 \pm 0.27$ & $1.70 \pm 0.16$ & -1.087 & 0.286 \\
Weight (kg) & $73.59 \pm 13.00$ & $69.98 \pm 15.14$ & 1.212 & 0.236 \\
\hline
\end{tabular}

Data are presented as mean \pm standard deviation

Independent t-test results showing comparisons be- tween the pulmonary functions of participants in the two groups are presented in table 2. 
Table 2: Comparisons between the pulmonary functions of tricyclists and non-tricyclists

\begin{tabular}{lllll}
\hline Variables & $\begin{array}{l}\text { Tricyclists } \\
(\mathbf{n}=\mathbf{1 5 0})\end{array}$ & $\begin{array}{l}\text { Non- } \\
\text { tricyclists } \\
(\mathbf{n}=\mathbf{6 0})\end{array}$ & t-value & p-value \\
& & & & \\
& & & & \\
FVC (L) & $1.75 \pm 0.78$ & $3.0 \pm 0.83$ & -10.364 & $<0.001^{*}$ \\
& & & & \\
FEV1(L) & $1.65 \pm 0.77$ & $2.87 \pm 0.84$ & -10.162 & $<0.001^{*}$ \\
& & & & \\
PEFR & $4.15 \pm 2.21$ & $4.78 \pm 1.19$ & -2.636 & $0.009^{*}$ \\
$(\mathrm{~L} / \mathrm{sec}$ (1) & & & & \\
& & & & \\
FEV1/FVC (\%) & 11.83 & & &
\end{tabular}

\footnotetext{
Key: $\mathrm{FVC}=$ forced vital capacity; FEV1= forced expiratory volume; PEFR= peak expiratory flow rate; *= significant at $\mathrm{p}<0.05$; normal range of $\mathrm{FVC}=5.5-4.75 \mathrm{~L}$; normal range of $\mathrm{FEV} 1=4.5-3.5 \mathrm{~L}$; Restrictive decrease in FVC with decrease in FEV1/FVC\% less than 85\%; decrease in FVC with no decrease in FEV1/FVC\% (ie it remains above $85 \%)^{28}$
}

The results showed significant differences in the FVC $(p<0.001)$, FEV $1(p<0.001), \operatorname{PEFR}(p=0.009)$ and FVC prediction result $(\mathrm{p}<0.001)$ of the participants in the two groups, with tricyclists showing lower values of pulmonary functions (table 2). However, there was no significant difference $(p=0.501)$ in the FEV1/FVC of the two groups.

The sp irometric results revealed prevalence of restric- tive pattern of pulmonary dysfunction among both groups of participants (tricyclists $-84.6 \%$; control $22.9 \%$ ) (Table 3). Positive weak correlations existed between duration of exposure and each of the pulmonary functions of the tricyclists (table 4).

Furthermore, the summary of tricyclists' self-reported respiratory symptoms (table 5) showed that the most commonly reported symptoms are cough $(46.0 \%)$, dust allergies (40.7\%) sneezing (34.0\%) and catarrh (30.0\%).

Table 3: Pulmonary abnormalities of the participants

\begin{tabular}{lll}
\hline $\begin{array}{l}\text { Interpretation of } \\
\text { spirometric results }\end{array}$ & Tricyclists n (\%) & $\begin{array}{l}\text { Control } \\
\text { n (\%) }\end{array}$ \\
\hline Restrictive pattern & $127(84.6)$ & $48(22.9)$ \\
Obstructive pattern & $21(14.0)$ & $12(5.7)$ \\
Normal & $2(1.3)$ & $0(0)$ \\
\hline
\end{tabular}

Restrictive - decrease in FVC with decrease in FEV1/FVC\% less than 85\%; decrease in FVC with no decrease in $\mathrm{FEV} 1 / \mathrm{FVC} \%$ (ie it remains above $85 \%$ ) $^{28}$ 
Table 4: Correlation between tricyclists' duration of exposure (years in tricycling occupation) and pulmonary functions

\begin{tabular}{lcccc}
\hline & FVC & FEV $_{1}$ & PEFR & FEV $_{1} / \mathrm{FVC} \%$ \\
\hline $\begin{array}{l}\text { Duration of } \\
\text { exposure }\end{array}$ & & & & \\
$\mathrm{r}$ - value & 0.214 & 0.246 & 0.237 & 0.201 \\
$\mathrm{r}^{2}$ - value & 0.046 & 0.061 & 0.056 & 0.040 \\
$\mathrm{P}$ - value & 0.132 & 0.082 & 0.094 & 0.158 \\
\hline
\end{tabular}

Key: $\mathrm{FVC}=$ forced vital capacity; FEV1 = forced expiratory volume; $\mathrm{PEFR}=$ peak expiratory flow rate

Table 5: Self-reported respiratory symptoms experienced by the tricyclists

\begin{tabular}{|c|c|c|}
\hline Variables & Yes n (\%) & No n (\%) \\
\hline Difficult breathing & $30(20.0)$ & $120(80.0)$ \\
\hline Cough & $69(46.0)$ & $81(54.0)$ \\
\hline Sneezing & $51(34.0)$ & $99(66.0)$ \\
\hline Wheezing & $26(17.3)$ & $124(82.7)$ \\
\hline Shortness of breath & $25(16.7)$ & $125(83.4)$ \\
\hline Catarrh & $45(30.0)$ & $105(70.0)$ \\
\hline Tightness in the chest & $30(20.0)$ & $120(80.0)$ \\
\hline Nasal or sinus allergies & $39(26.0)$ & $111(74.0)$ \\
\hline $\begin{array}{l}\text { More than } 6 \text { respiratory } \\
\text { infections in a year }\end{array}$ & $0(0.0)$ & $150(100)$ \\
\hline Dust allergy & $61(40.7)$ & $89(59.3)$ \\
\hline
\end{tabular}




\section{Discussion}

This study evaluated the pulmonary functions of tricyclists in Enugu, Nigeria. It was revealed that there was a highly significant decrease in FVC, FEV1, and PEFR in tricyclists, compared to age-and sex-matched non-tricyclists. These findings corroborate the results of previous studies which showed significant decreases in $\mathrm{FVC}^{18,19}, \mathrm{FEV}^{118,19}$, $\mathrm{PEFR}^{19}$ of tricyclists in India. These decreased pulmonary functions are indicators of the adverse effects of vehicle exhaust and other air pollutants on lung functions, particularly lower airways with restrictive pattern of lung disease ${ }^{18}$. Similar findings have been reported in other road workers, including taxi drivers ${ }^{25}$, traffic officers ${ }^{26}$ and commercial bus drivers $^{27}$, who are constantly exposed to traffic air pollutants.

In a developing country like Nigeria, the roads are densely polluted by dangerous fumes and vehicle emissions as welas frequent traffic jams ${ }^{28}$. Prolonged exposure to environmental pollutants such as automobile exhausts is a predisposing factor of pulmonary abnormalities, including decrease in lung compliance and function $^{29,30}$, lung diseases, chronic bronchitis, asthma attacks and other respiratory illness ${ }^{30}$.

However, this study showed no significant reduction in FEV1/FVC of the tricyclists, as compared to the control group. As a matter of fact, most of the participants (about 80\%) showed normal values of FEV1/ FVC (above 85\%), in addition to the reduced FVC levels. Several studies18,29,31 also observed no significant decrement in FEVI/FVC values of tricyclists in Pune, Gulbarga and Bangalore cities, respectively. The spirometric values of the participants of the present study are suggestive of the restrictive pattern of pulmonary disease which is characterized by significant decrease in $\mathrm{FVC}$ with no decrease in $\mathrm{FEVI} / \mathrm{FVC} \%$ (remaining above $85 \%)^{31}$.

This study revealed that majority of the participants in both groups showed restrictive patterns of lung disease. This can be attributed to the diminished ambient air quality in Nigeria ${ }^{11-14}$. Specifically, 125 out of 150 tricyclists $(83.3 \%)$ showed restrictive patterns of lung disease in the present study. Babu and Damoder ${ }^{31}$ attributed high prevalence of restrictive lung disease in tricyclists to four possible mechanisms. First is the decrease in lung functions as a result of exposure to particulate matter and ozone in the air ${ }^{32}$; secondly, inhalation of nitrogen oxide in air results in terminal alveolar damage with resultant decrease in pulmonary compliance and lung functions ${ }^{32}$. Thirdly, exposure to ozone in the air results in lung stiffening ${ }^{33}$ and pulmonary fibrosis while the fourth mechanism is the weakening effect of carbon monoxide on the respiratory muscles ${ }^{34}$.

Additionally, this study revealed no significant correlation between the tricyclists' duration of exposure to environmental pollutants and pulmonary functions, although it was observed that tricyclist who had worked for more than three years showed marginally lower pulmonary function values, as compared to those who had worked for less than 3 years. Farooque and Jayachan$\mathrm{dra}^{19}$ reported that the pulmonary functions of tricyclists who had worked for more than ten years were more affected than those who had worked for less than ten years. Rajkumar ${ }^{3}$ had also reported a gradual decline in pulmonary functions in association with increased duration of exposure to environmental pollutants. Further related studies with larger sample sizes may yield more generalizeable findings on the correlation between duration of exposure and severity of pulmonary abnormalities in tricyclists.

Furthermore, findings from investigation of the tricyclists' respiratory symptoms revealed the prevalence of some respiratory symptoms among the tricyclists. The commonest symptoms reported by the tricyclists included cough, dust allergies, sneezing and catarrh. This result was expected as several studies ${ }^{10,35,36}$ have implicated immune system impairment, asthma and other chronic respiratory diseases to exposure to ambient air pollutants.

\section{Conclusion}

Pulmonary functions of tricyclists are significantly decreased, as compared to age-and sex- matched individuals. This study confirms that tricyclists are at increased risk of pulmonary abnormalities, resulting from occupational exposure to outdoor pollutants. Restrictive pattern of pulmonary abnormalities are most prevalent in tricyclists. There is urgent need to educate tricyclists on the use of protective devices such as face masks for reduced risk of pollutant inhalation.

\section{Limitations of the study}

The convenience sampling technique used in this study may have introduced some selection bias. Secondly, the inclusion of tricyclists with 1-year exposure to occupational pollutants may have influenced the study findings as this duration of exposure may not have been sufficient to effect significant changes that may warrant clinical concern. 
Finally, lack of information on the intra- and inter-rater reliability of the equipments (weighing scale and stadiometer) used for anthropometric measurements may have also affected the reliability of the obtained results.

\section{Acknowledgement}

The authors appreciate the study participants for their time and participation in the study.

\section{Conflict of interest disclosure}

The authors declare no conflict of interest.

\section{References}

1. Atubi AO. Transport and the Environment: Towards reducing road traffic emissions in Nigeria. International Journal of Science and Technology (STECH) 2015; 4(1):58-78.

2. Grieshop AP, Boland D, Reynolds CCO, Gouge B, Apte JS, Rogak SN, Kandlikar M. Modelling air pollutant emissions from Indian auto-rickshaws, model development and implications for fleet emission rate estimates. Atmospheric Environment 2012; 50: 148-156.

3. Rajkumar. Effect of air pollution on Respiratory system of auto rickshaw drivers in Delhi. Indian Journal of Occupational and Environmental Medicine 1999; 3(4):171173.

4. Onursal B, Gautam SP. Vehicle air pollution: Experiences from seven latin American urban centre. Technical paper 1997; 373. Washington DC: World Bank.

5. Ojolo SJ, Oke SA, Dinrifo RR, Eboda FY. A survey on the effects of vehicle emissions on human health in Nigeria. Journal of Rural and Tropical Public Health 2007; 6:16-23.

6. Sydbom A, Blomberg A, Pamia S, Stenfors N, Sandstrom T, Dahlen SE. Health Effects of Diesel Exhaust Emissions. European Respiratory Journal 2001; 7(4): 733746.

7. Brunekreef B. Out of American commentary occupation. Environmental Medicine 2005; 62:351-352

8. Han X, Naeher LP. A review of traffic-related air pollution exposure assessment studies in the developing world. Environment International 2006; 32:106-120

9. Savile SB. Automotive options and quality management in developing countries. Indian Journal of Environmental Health 1993;16:20-32

10. Ekpenyong CE, Ettebong EO, Akpan EE, Samson TK, Daniel NE..Urban city transportation mode and respiratory health effect of air pollution: a cross-sectional study among transit and non-transit workers in Nigeria. British Medical Journal 2012; 2(5)
11. Abam FI, Unachukwu GO. Vehicular emissions and air quality standards in Nigeria. European Journal of Scientific Research 2009; 34(4): 550-560.

12. Njoku KL, Rumide TJ, Akinola MO, Adesuyi AA, Jolaoso AO. Ambient air quality monitoring in metropolitan city of Lagos, Nigeria. Journal of Applied Sciences and Environmental Management 2016; 20(1): 178-185.

13. Akinfolarin OM, Boisa N, Obunwo CC. Assessment of Particulate Matter-Based air quality Index in Port Harcourt, Nigeria. Journal of Environmental Analytical Chemistry 2017. 4(4): 224.

14. Chizoruo IF, Iheanyichukwu OA, Chukwuemeka NP, Ikechukwu AJ. Ambient Air Quality Assessment of Orlu, Southeastern, Nigeria. Journal of Applied Sciences 2017; 17(9): 441-457.

15. Alexander IA, Ya MG, Yalwa MG, Alhassan AJ, Nels RO, Nelson NO, Muhammad IU. Determination of Lead and some Parameters of Oxidative Stress in Exhaust Fume in Relation to Age in Commercial Tricyclists in Kano Municipal in Commercial Tricyclists in Kano Municipal. International Journal of Medical Science and Applied Biosciences 2017; 2(2): 11-35.

16. Scheepers PT, Bos RP (1992). Combustion of diesel fuel from a toxicological perspective. I. Origin of incomplete combustion products. International Archives of Occupational and Environmental Health 1992; 64 (3): 149-161.

17. Kampa M, Castanas E. Human health effects of air pollution. Environmental Pollution 2007; 151(2):362-367. Doi: 10.1016/j.envpol.2007.06.012.

18. Afroz AB, Manujushree S, Amrutha SI. A Comparative Study Among The Three Wheeler Automobile Drivers On Pulmonary Function Tests In Adult Males Of Gulbarga City. International Journal of Medical Research and Health Sciences 2012; 2(1), 35-39

19. Farooque I, Jayachandra S. Pulmonary function tests in non-smoking auto rickshaw drivers. Al Ameen Journal of Medical Sciences 2014; 7(3): 240-243

20. Cohen J. Statistical Power Analysis for BehaviouralScienecs. 2nd ed. Hillsdale, New Jersey: Lawrence Erlbaum Associate 1998.

21. Sharma G, Goodwin J. Effect of aging on respiratory system physiology and immunology. Clin Interv $A g$ ing 2006; 1(3): 253-60.

22. Pruthi N, Multani NK. Influence of Age on Lung Function Tests. Journal of Exercise Science and Physiotherapy 2012; 8(1): 1-6.

23. American Thoracic Society. Standardisation of spirometry 1994 Update. American Journal of Respiratory and Critical Care Medicine 1995; 152(3):1107-1136. 
24. Cotes JE, Chinn DJ. MRC questionnaire (MRCQ) on respiratory symptoms. Occupational Medicine 2007; 57(5): 388-388.

25. Bener A, Brebner J, Atta M, Gomes J, Ozkaragoz F, Cheema M. Respiratory symptoms and lung functions in taxi drivers and manual workers. Aerobiologia 1997; 13(1): 11-15.

26. Raina V, Sunil S, Rajiv KG. Study of pulmonary function tests of traffic policemen in Jammu Region. $J K$ Science 2014; 16 (3): 122-124.

27. Jones AY, Lam PK, Dean E. Respiratory health of bus drivers in Hong Kong. International Archives of Occupational and Environmental Health 2006; 79(5): 414-418./ span>

28. Baumbach G, Vogt U, Hein KRG, Oluwole AF, Ogunsola OJ, Olaniyi HB, Akeredolu FA. Air pollution in a large tropical city with a high traffic density-results of measurements in Lagos, Nigeria. Science of the Total Environment 1995; 169(1-3): 25-31.

29. Gavali S, Kharche JS, and Pranita A. Prevalence of restrictive lung disorders in auto rick shaw drivers. Indian Journal of Applied Basic Medical Sciences 2012; 14 (19): 13-21.

30. Ambient (outdoor) air quality and health Fact sheet No313 WHO update [database on the Internet] 2011
Updated March 2014. Available from: http://www. who.int/mediacentre/factsheets/fs313/en/

31. Babu VK, Damodar KS. (2017). Effect of outdoor air pollution on pulmonary function of non-smoking auto-rickshaw drivers in Bangalore. International Journal of Clinical and Experimental Physiology 2017; 4(1): 30.

32. Uysal N, Schapira RM. Effects of ozone on lung function and lung diseases. Current Opinion on Pulmonary Medicine 2003; 9(2):144-150.

33. Costa DL, Tepper JS, Stevens MA, Watkinson WP, Doerfler DL, Gelzleichter TR. Restrictive lung disease in rats exposed chronically to an urban profile of ozone. American Journal of Respiratory and Critical Care Medicine 1995; 151(5):1512-1518.

34. Hart N, Cramer D, Ward SP, Nickol AH, Moxham J, Polkey MI. Effect of pattern and severity of respiratory muscle weakness on carbon monoxide gas transfer and lung volumes. European Respiratory Journal 2002; 20(4):996-1002.

35. Schwela D. Air pollution and health in urban areas. Reviews on Environmental Health 2000; 15(12): 13-24.

36. Mustapha BA, Blangiardo M, Briggs DJ, Hansell AL. Traffic air pollution and other risk factors for respiratory illness in schoolchildren in the niger-delta region of Nigeria. Environmental Health Perspectives 2011; 119(10): 1478-1482. 